\title{
Optimization of Rigidly Supported Guyed Masts
}

\author{
R. Belevičius, ${ }^{1}$ D. Jatulis, ${ }^{2}$ D. Rusakevičius, ${ }^{3}$ and D. Mačiūnas ${ }^{3}$ \\ ${ }^{1}$ Department of Information Technologies, Vilnius Gediminas Technical University, Sauletekio Al. 11, LT-10223 Vilnius, Lithuania \\ ${ }^{2}$ Department of Bridges and Special Structures, Vilnius Gediminas Technical University, Sauletekio Al. 11, LT-10223 Vilnius, Lithuania \\ ${ }^{3}$ Department of Engineering Mechanics, Vilnius Gediminas Technical University, Sauletekio Al. 11, LT-10223 Vilnius, Lithuania
}

Correspondence should be addressed to R. Belevičius; rimantas.belevicius@vgtu.lt

Received 9 February 2017; Accepted 23 April 2017; Published 29 May 2017

Academic Editor: Luigi Di Sarno

Copyright (C) 2017 R. Belevičius et al. This is an open access article distributed under the Creative Commons Attribution License, which permits unrestricted use, distribution, and reproduction in any medium, provided the original work is properly cited.

A technique for simultaneous topology, shape, and sizing optimization of tall guyed masts is presented in this paper. The typical scheme of telecommunication masts that are triangular in plan and supported by a certain number of guys' levels is examined. The objective function is the total mass of the mast, including the mass of the guys. The mast structure is optimized for self-weight and wind loading that is evaluated according to Eurocodes. The nonlinear behaviour of the guyed mast is simplified idealizing the nonlinear guys as approximate boundary conditions for the mast. A comparison of the simplified solution with the results of nonlinear analysis with Ansys shows small discrepancies that are on the safe side. The constraints involve all strength, local and global stability, and slenderness requirements. The optimization problem is solved using evolutionary algorithm with original genome repair procedure. As an example, a typical $96 \mathrm{~m}$ guyed broadcasting antenna for mobile-phone networks was designed employing the proposed optimization technique and taking up to 10 guys' levels. It is shown that the optimal mast is supported by 3-5 guys' levels. The optimal ranges of all remaining design variables were also obtained.

\section{Introduction}

In recent years the development of telecommunication networks has stimulated the amount of design and construction of tall steel-guyed masts. The mast structures are usually produced and constructed in certain quantities as typical structures depending on the terrain conditions and required area of antennas. Therefore, research, innovation, and cost optimization of guyed masts are a relevant engineering problem.

The guyed masts are supported by prestressed guy cables attached to the shaft of the mast at different levels. These cables exhibit nonlinear behaviour and are very sensitive to their geometry and prestress levels; therefore, despite the elastic behaviour of the mast shaft, these structures should be analysed by a nonlinear analysis program. The shaft is usually composed of a number of sections of identical structure and dimensions; one section comprises shaft legs, stiffeners between legs of the shaft, and oblique bracing elements. One example of triangular mast and the structure of the shaft are shown in Figures 1 and 2.
The problem of analysis of a guyed mast is even more complicated since the dominant loading on the mast is turbulent wind, and the dynamic effects cannot be neglected in a reliable analysis.

Those nonlinear prestressed structures were analysed in a number of research papers, for example, Gantes et al. [1] and Smith [2]. Different analytical and computational methods for evaluation of the strain-stress behaviour were suggested by Wahba et al. [3], He et al. [4], and Gioffrè et al. [5]. Several researchers pursued improvements of mast structure seeking the least possible weight (synonymous with cost) of the structure (Jasim and Galeb [6]). In most cases refinement of the structure was understood exclusively as selection of the geometrical scheme of shaft elements, that is, leg, bracing, and stiffener members, and the dimensioning of cross sections. However, the maximum effectiveness of those structures can be achieved by simultaneously tuning all the topological, geometric, and physical parameters.

The topology of the guyed mast is identified by the number of the guys' clusters, the number of guys' anchors to the ground, the geometric scheme of a typical shaft section, 

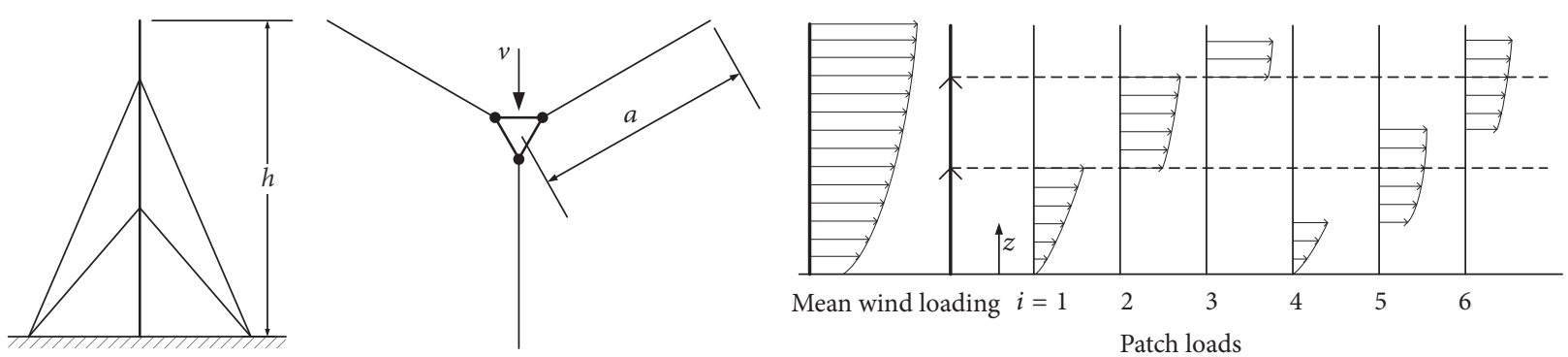

FIgURE 1: Typical mast with two clusters of guys. Horizontal plan of the mast.

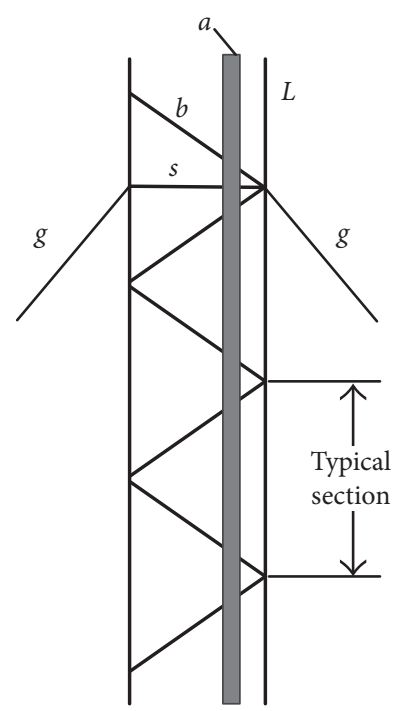

FIgURE 2: Structure of the shaft: $L$ : leg, $b$ : bracing, $s$ : stiffener members, $g$ : guy, and $a$ : auxiliary equipment.

and the shaft-ground connection scheme. Some of these parameters were chosen before the optimization. For example, it is obvious (and it is explicitly shown in [7]) that the mast of the triangular horizontal plan is lighter than the square plan mast. Thus, only the triangular mast is considered. As to the shaft-ground connection scheme, two schemes prevail in the engineering practice: pinned at the foundation and fixed. In the pinned masts the stresses in the leg are distributed more evenly. In fixed masts the horizontal displacements of the shaft cause significant bending moments at the support, and the maximum stresses develop in the lowest sections of the mast. Such uneven distribution of stresses is not rational and results in a substantially heavier structure compared with the pinned masts. However, pinned masts have inherent deficiencies. Firstly, the shaft must be strutted at the assembly stage of mast construction. Secondly, the hinged connection at the support does not provide the torsional stiffness of the mast; therefore, either the antitwist tackle ("mounting star") or sophisticated support construction that does not transfer the bending moment but assures the required torsional stiffness must be provided [8]. Due to these drawbacks of the pinned scheme, in this paper the mast scheme that is fixed at the foundation is considered.
The shape of the mast is defined by the vertical locations of the guy attachments to the shaft, the horizontal locations of the guy anchors on the ground, the width of the shaft, and the height of a typical section. The sizing parameters include cross sections of all structural elements of the shaft and cross sections of guys. All leg, bracing, and stiffener elements are round solid steel bars and are of constant diameter along the mast height. In addition, the pretension forces have to be chosen in guys at all levels.

The aim of this paper is twofold: to suggest the technique enabling the use of a classical EA with special genome repair procedure for optimization of guyed masts and to obtain the optimal scheme of a typical $96 \mathrm{~m}$ tall mast. The suggested technique should yield the optimal, that is, lightest, scheme for a mast with "one button click" using the following initial data for the structure:

(i) Height of the mast

(ii) The geometrical scheme of the typical mast section

(iii) The geometrical dimensions of auxiliary equipment and antennas

(iv) Material data of structural elements and guys (Young's moduli, specific weights; material is treated as isotropic)

(v) Maximum allowable stresses in elements and guys

(vi) Maximum allowable deflection at the top of the mast

(vii) Loading data

(viii) Lower and upper limits for radii of leg, bracing, stiffener members, and guys

In mathematical terms, the mast optimization problem is a mixed integer global optimization problem, since the landscape of objective function is not known and cannot be obtained in a closed form. The results of numerical experiments presented in this paper definitely show that the problem is really multimodal. Since the number of design parameters is large, we use the stochastic optimization algorithms, which do not require the sensitivity information. The stochastic algorithms do not guarantee the global solution of a problem, but in the engineering practice it is more important to find a rational solution that is better than the solution currently known.

In $[9,10]$ we optimized the triangular mast with two clusters of guys using genetic algorithms and simulated 
annealing and revealed the dominant parameters for optimal design. In [11] the typical $96 \mathrm{~m}$ broadcasting antenna for mobile-phone networks with an arbitrary number of guys' clusters employing an evolutionary algorithm (EA) from Matlab [12] was optimized. Comparison of optimized mast structure with the typical industrial design revealed possibilities for significant reduction of steel expenditure. However, the simplified algorithm for evaluation of computational length between adjacent clusters of guys led to a so-called "checkerboard effect": finer structural elements conditioned better objective function values, and some threshold values were needed to prevent excessive refinement of the structure. In this paper the exact computational lengths were used for checking the global stability constraints, and a special genome repair procedure was employed in EA. It is shown that the mass of the mast is significantly reduced by installing at least three guys' clusters: the reduction of mass is up to $40 \%$ for a three-guy-level mast compared to a two-level one, but starting from the five-level mast the mass slightly increases. Also, the optimal ranges of the determinant design parameters are discussed.

\section{Problem Formulation}

2.1. Idealizations. The structural behaviour of guyed masts is extremely complicated. The guys exhibit geometrically nonlinear behaviour and more at low pretensioning levels. Increasing the pretension forces decreases the nonlinearity and enhances lateral stiffness but simultaneously increases compressive loads and herewith the buckling probability for the mast. The mast itself can be also geometrically nonlinear due its slender structure. In addition to the substantial wind loads, the loads due to the self-weight of the mast with all auxiliary equipment and possible icing should be accounted for.

The use of optimization algorithms with tens of design parameters supposes analysing the mast structure and obtaining the objective function for any number of times. Therefore, a very fast and reliable analysis tool is a pure necessity, and we restrict the analysis only to the linear stage, approximately substituting the guys by the springs and compression forces on the shaft of the mast. The horizontal stiffness of springs is proportional to the displacements at the guy attachment node, and the vertical compression forces depend first of all on the prestress in the guy. The geometrically nonlinear verification solution of the same mast structure via finite element package Ansys proves these approximate assumptions are always on the safe side. In the Ansys solution the guys are represented by cable elements; each guy is divided into 10 elements. In Figure 3 both solutions for the horizontal displacements in the opposite direction to the wind are compared for the obtained best mast scheme: the 5 guys' cluster mast. All geometrical data are presented in Table 2. The discrepancies in horizontal displacements are higher at the middle levels of the mast, but the differences in displacements of nodes at the mast top do not exceed 2\% (Figure 3). Since higher displacements obtained by linearized simplified solution also cause higher stresses in the rigidly supported mast, the constraints (see (6)-(8), Section 2.2) slightly narrow the search space of

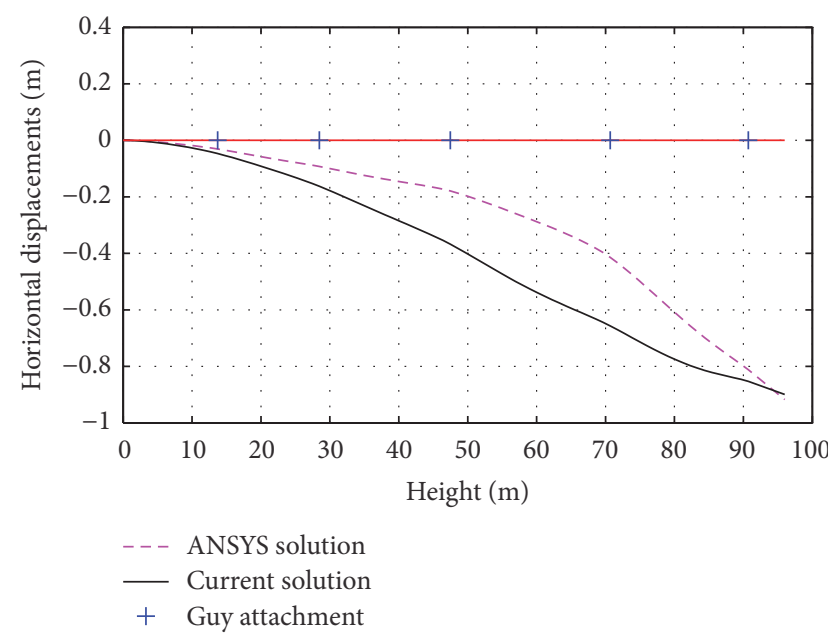

FIgure 3: Comparison of the idealized solution with the Ansys solution.

optimization problem to the safer side. More important here is the coincidence of displacements at the mast top: analysis of the intermediate results of optimization reveals that the constraint most difficult to satisfy is the given maximum lateral displacement of the mast top.

The next simplifying assumption concerns the turbulent wind loading on the structure. Instead of dynamic loading, we evaluate the corresponding static wind loads by the patchload method (Eurocode 1, Part 1-4 [13], and Eurocode 3, Part 3-1 [14]) which adequately mimics the dynamic behaviour of the structure and solve the static problem. According to the Eurocodes, the designer has to consider several other loadings in addition to the wind loading of different directions, including icing and several of their combinations. In this paper we choose to optimize the mast for the most critical and determinant case of wind loading, when the direction of the wind is at a right angle to one side of the mast. The loads due to the self-weight of the structure and equipment are accounted for, but not the ice loads. Simultaneous icing and extreme winds are more topical for Nordic and mountainous countries only. However, our meshing program has the straightforward capability of including icing loads of the required type and class according to the European standard on atmospheric icing [15].

Subsequently, after rounding the obtained values of continuous design parameters to suitable values (e.g., geometrical dimensions, to in-stock values), the designer may verify the scheme employing the more accurate nonlinear analysis and taking into account other loading cases. Therefore, the optimization technique presented can be useful during the preliminary mast design stage, supplying the designer with hints for the topology and shape of the mast, as well as geometrical data on all structural elements.

2.2. Optimization Problem and Technique. The complete set of programs consists of four independent parts: the optimization algorithm, meshing program that renders the set of design parameters to the discretized model of the mast 
TABLE 1: Set of design parameters.

\begin{tabular}{|c|c|c|c|c|}
\hline Parameter & Type & Quantity of parameters & Lower bound & Upper bound \\
\hline Number of guys' clusters, $n_{g}$ & Integer & 1 & 1 & 10 \\
\hline Number of typical shaft sections, $n_{s}$ & Integer & 1 & 6 & 120 \\
\hline Levels of guys' clusters, in sections from the ground, $l$ & Integer & $n_{g}$ & $n_{s} / 20$ & $n_{s}$ \\
\hline Distances of guy anchors from the shaft, $d(\mathrm{~m})$ & Continuous & $n_{g}$ & 5 & 100 \\
\hline Width of the shaft, $w(\mathrm{~m})$ & Continuous & 1 & 0.20 & 2.40 \\
\hline Radius of the leg elements, $r_{l}(\mathrm{~m})$ & Continuous & 1 & 0.008 & 0.040 \\
\hline Radius of the bracing and stiffener elements, $r_{b}(\mathrm{~m})$ & Continuous & 1 & 0.008 & 0.030 \\
\hline Radius of guys, $r_{g}(\mathrm{~m})$ & Continuous & 1 & 0.001 & 0.010 \\
\hline Pretension forces in guys, $f(\mathrm{~N})$ & Continuous & $n_{g}$ & 5000 & 30,000 \\
\hline
\end{tabular}

structure, finite element analysis program, and program for evaluation of objective function value.

The genetic algorithm with preprocessor for genome repair is used as the primary optimization engine. After the best solution from the set of EA solutions is selected, the pattern search algorithm [16] is employed to explore the neighbourhood of the solution in depth and (probably) improve it.

The meshing program is used as a preprocessor for the finite element program. It inputs the set of design parameters produced by the optimization algorithm together with data which do not vary in the optimization process (e.g., mast height, wind velocity, and material characteristics) and prepares the complete dataset for the finite element program. All loadings including self-weight and wind loads on the structure are recalculated using new values of all geometrical parameters.

A fast finite element program is required; hence an original problem-oriented Fortran program was developed for the static analysis. All the structural elements of the shaft are represented by beam elements. Instead of guys at the guy attachment nodes, the horizontal stiffness boundary conditions and corresponding vertical compression forces are applied.

After the finite element analysis, the postprocessor program evaluates the value of the objective function, verifies all constraints, and transmits the objective function value to the optimization engine, which prepares a new estimate of design parameters set on its basis.

In mathematical terms, the optimization problem is formulated as follows:

$$
f^{*}=\min _{x \in D} f(x)
$$

subject to

(i) structure equilibrium constraints,

(ii) strength constraints in all structural elements of the shaft and guys,

(iii) local stability constraints in all leg and bracing elements,

(iv) global stability constraints between the clusters of guys and between the lower cluster and mast foundation, (v) slenderness constraints in all leg and bracing elements,

(vi) lateral stability constraint of the mast top.

$f(x)$ in (1) is a nonlinear objective function of continuous and integer variables $f: \mathfrak{R}^{n} \rightarrow \mathfrak{R}, n$ is the number of design parameters $x$, and $D \in \mathfrak{R}^{n}$ is a feasible region of design parameters. The global minimum should be found. No assumptions on unimodality are included into formulation of the problem; that is, many local minima may exist.

The total mass of the mast, including the mass of the guys, is considered in the objective function. Since the material of the guys is more expensive, the mass of the guys is premultiplied by a factor given by the program user. The cost of guy anchors and the cost of connections can also be included into the objective function in a similar manner.

The complete set of design parameters, along with their characteristics and bounds, is listed in Section 3, Table 1.

All strength, stability, and slenderness constraints are assessed according to Eurocode 3, Part 3-1 [14], and Eurocode 3, Part 1-1 [17]. The overall structure equilibrium constraints are checked solving the static problem with the finite element program. The typical 2-node beam elements with 12 degrees of freedom are used to represent the structural elements of the shaft. The main statics equation is

$$
[K]^{a}\{u\}^{a}=\{F\}^{a},
$$

where $[K]^{a}$ is the stiffness matrix, $\{u\}^{a}$ are nodal displacements, and $\{F\}^{a}$ are the active forces of the ensemble of elements. The element stiffness matrix can be found in many textbooks, for example, [18]. The stress resultants in all finite elements according to [14] are

$$
S_{\mathrm{TM}}=S_{M} \pm S_{p}
$$

where $S_{M}$ is stress due to the static wind load on the whole mast height plus the dead weight of the mast structure and $S_{p}$ is cumulative stress due to the pseudo-dynamic loads on the patches of the mast according to [13]; the number of load cases for $n_{g}$ guys' clusters is $2\left(n_{g}+1\right)+1$. Thus, (2) has to be solved for $2\left(n_{g}+1\right)+2$ times.

The influence of guys on the behaviour of the shaft is modelled by linear stiffness boundary conditions. The total stiffness estimation of the guys in a guys' cluster when the 
TABLE 2: Optimal mast parameters at 1-10 guys' clusters.

\begin{tabular}{|c|c|c|c|c|c|c|c|c|}
\hline$n_{g}$ & $\begin{array}{c}m_{E A} \\
m_{E A+P S} \\
(\mathrm{~kg})\end{array}$ & $w(\mathrm{~m})$ & $n_{s}$ & $r_{l}(\mathrm{~m})$ & $r_{b}(\mathrm{~m})$ & $r_{g}(\mathrm{~m})$ & $N_{f}$ & $T(\mathrm{~h})$ \\
\hline 1 & $\begin{array}{l}21713 \\
21712\end{array}$ & 1.99 & 38 & 0.0430 & 0.0184 & 0.010 & 613030 & 4.87 \\
\hline 2 & $\begin{array}{c}11018 \\
10983\end{array}$ & 1.18 & 57 & 0.0281 & 0.0123 & 0.0081 & 629430 & 11.19 \\
\hline 3 & $\begin{array}{l}6974 \\
6940\end{array}$ & 0.86 & 72 & 0.0226 & 0.0101 & 0.0055 & 692630 & 12.68 \\
\hline 4 & $\begin{array}{l}5913 \\
5862\end{array}$ & 0.69 & 82 & 0.0206 & 0.00855 & 0.00489 & 696230 & 13.90 \\
\hline 5 & $\begin{array}{l}5538 \\
5459\end{array}$ & 0.69 & 91 & 0.0191 & 0.00810 & 0.00459 & 683230 & 15.40 \\
\hline 6 & $\begin{array}{l}5860 \\
5475\end{array}$ & 0.68 & 83 & 0.0195 & 0.00811 & 0.00447 & 719430 & 17.54 \\
\hline 7 & $\begin{array}{l}5984 \\
5682\end{array}$ & 0.625 & 83 & 0.0195 & 0.0081 & 0.00464 & 749630 & 21.27 \\
\hline 8 & $\begin{array}{l}6043 \\
5828\end{array}$ & 0.86 & 90 & 0.0178 & 0.0080 & 0.00437 & 772430 & 23.72 \\
\hline 9 & $\begin{array}{l}6396 \\
6005\end{array}$ & 0.79 & 88 & 0.0183 & 0.0080 & 0.00441 & 810430 & 26.26 \\
\hline 10 & $\begin{array}{l}6891 \\
6371\end{array}$ & 0.83 & 90 & 0.0182 & 0.0080 & 0.00444 & 784430 & 26.80 \\
\hline
\end{tabular}

wind blows toward one guy is given by Gantes et al. [1]. However, this case is not critical for the mast fixed at the foundation. The shaft of the mast receives larger displacements in the opposite wind direction. Now two stressed guys absorb all wind action, while the third guy is slack and provides only compression force mainly due its pretension force. In this case we obtain different stiffness' expression of one windward guy:

$$
k=\frac{1}{2} \frac{l_{x} A_{g} E}{c^{2}\left(1+\left(m g l_{x} / T_{p}\right)^{2}\left(A_{g} E / 12 T_{p}\right)\right)},
$$

where $l_{x}$ is the distance of the guy foundation from the axis of the shaft, $A_{g}$ is the guy cross section area, $E$ is Young's modulus of guy material, $c$ is the length of the guy, $m g$ is the dead weight of the guy per unit length, and $T_{p}$ is the pretension force in the guy.

The compressive effects of one set of guys are idealized by the vertical compressive forces applied to the guy attachment nodes:

$$
p=n_{g c} T_{p} \frac{H}{c}
$$

where $n_{g c}$ is the number of guys in one guys' cluster and $H$ is the height of the mast. Our assumptions (4) and (5) are checked via nonlinear modelling of the mast with guys and are of sufficient precision (Figure 3 ). The spring stiffness according to (4) is slightly less than the stiffness of the real guy but the error is to the safe side.

The first of the inequality constraints, the strength constraints, are checked in all structural elements of the mast, accounting for both the axial force $N$ and bending moment $M$ for the allowable stress $\bar{\sigma}$ :

$$
\sigma=\left|\frac{N}{A} \pm \frac{M}{W}\right| \leq \bar{\sigma}
$$

The stability requirements for the leg and bracing members are posed according to Eurocode 3, Part 3-1 [14]:

$$
|N| \leq \frac{\chi A f_{y}}{\gamma_{M 1}}
$$

where $A$ is the cross section area of the member and $f_{y}$ is the steel yield point (dependent on the diameter of the member). According to [14], the partial factor of resistance of the members to member buckling $\gamma_{M 1}$ is taken to be 1.0, and reduction factor coefficient $\chi$ is evaluated via complex engineering formulas depending on the nondimensional slenderness of structural elements.

The global stability requirements between adjacent clusters of guys are expressed in the form of a mast segment buckling condition due to the equivalent compression force $N_{E d}$ and the equivalent bending moment $M_{E d}$ in the cross section of the mast:

$$
\frac{N_{E d}}{\chi_{y} N_{R k} / \gamma_{M 1}}+\frac{M_{E d}}{\chi_{L t}\left(M_{y, R k} / \gamma_{M 1}\right)} \leq 1,
$$

where $\chi_{y}$ is the reduction factor for the relevant buckling mode, $N_{R k}$ is the cross section axial resistance, and $M_{y, R k}$ is the cross section moment resistance (based on either the 
plastic, elastic, or effective section modulus, depending on classification). Details on the evaluation of these coefficients may be found in Eurocode 3, Part 1-1 [14].

The slenderness constraints for the mast segments between clusters of guys and slenderness constraints for bracing members, correspondingly, are

$$
\begin{aligned}
& \lambda \leq 120, \\
& \lambda \leq 180 .
\end{aligned}
$$

Obtaining the buckling length of a mast segment needed for assessment of the stability constraint takes significant numerical effort. In [11] we used an approximate value of buckling length that was equal to the segment length; this is adequately accurate for a mast supported by 1-4 guys' clusters. For a mast supported by a larger number of guys' clusters it led to unrealistic designs, when the mass of the mast steadily decreases with the increasing number of guys' clusters. In this research the $i$ th segment buckling length is obtained with an empirical computational length coefficient:

$$
\mu_{i}=\sqrt{0.89005775+\frac{7.4379952}{m_{i}}},
$$

where $m_{i}$ is the coefficient of the segment support stiffness with regard to the shaft stiffness $E I$, dependent on the total stiffness provided by the guys $v_{i}$ :

$$
m_{i}=\frac{v_{i} l_{i}^{3}}{E I},
$$

where $l_{i}$ is the length of the $i$ th segment between adjacent guys' clusters. The coefficient $\mu_{1}$ for the segment between foundation and the first guys' level is obtained with a more awkward procedure:

$$
\mu_{1}=\frac{\mu_{\mathrm{avg}}}{k}
$$

where

$$
\begin{aligned}
\mu_{\mathrm{avg}} & =\sqrt{0.89005775+\frac{7.4379952}{m_{\mathrm{avg}}}}, \\
m_{\mathrm{avg}} & =\frac{\sum_{i} m_{i}}{n_{s g}}, \\
k & =\frac{\left(1+u_{1} / u_{2}+u_{1} / u_{3}+\cdots+u_{1} / u_{n}\right)}{n_{s g}}, \\
u_{i} & =\frac{l_{i}}{2} \sqrt{\frac{N_{E d}}{E I}}
\end{aligned}
$$

with $n_{s g}$ being the number of segments.

Finally, the lateral displacement $d$ of the mast top is constrained to one percent of the height of the mast.

The classical real coded genetic algorithm for solving mixed integer optimization problems MI-LXPM [19] was employed as a primary optimization engine. The meshing,
FEM analysis, and postprocessor programs are connected to the optimization algorithm as "black boxes." The main genetic parameters, population size, number of generations, probabilities of mutation and crossover, and so on, are tuned to the problem solved. The complete list of genetic parameters is presented in Section 3.

The list of design parameters along with their lower and upper bounds is presented in Table 1. Some of the parameters are interdependent (e.g., the guys cannot intersect or be attached to a nonexisting shaft section); therefore, in the initial stage of optimization-random generation of individuals - only the viable or repaired individuals are included into the initial population. For example, at the random generation of one particular individual of the initial population the following data was obtained: the number of guys' clusters $n_{g}=3$, number of sections $n_{s}=50$ (let the upper bound for $n_{s}$ be 100), and levels of guys' clusters $l_{1}=10, l_{2}=$ 60 , and $l_{3}=80$. In order to repair this infeasible individual, the levels are scaled down proportionally: $l_{1}=5, l_{2}=30$, and $l_{3}=40$.

Different conditions hold for the invalid individuals of the next generations obtained due to the mutation or crossover. Since the main idea of optimization technique to keep all constituent programs independent, the obtained infeasible guys' levels are repaired but the individuals with intersecting guys are retained. However, with an additional sufficient penalty given by the preprocessor of the finite element program, the finite element analysis for these individuals is not executed. The penalty is proportional to the number of such violations and acts like a "dead" penalty, fairly reducing the chances of infeasible individuals surviving the selection.

After the best EA solution is selected, the neighbourhood of the solution is explored with the pattern search (PS) algorithm. For optimization problems with a larger number of design parameters, it slightly improves the solution by $3-6 \%$.

\section{Numerical Examples and Discussion}

As an example, we optimize the $96 \mathrm{~m}$ tall guyed telecommunication mast that is produced by the steel industries. The industrial mast of triangular horizontal plan has four guys' clusters anchored at two points 32 and $59.5 \mathrm{~m}$ from the shaft. The width of shaft is $1.20 \mathrm{~m}$. All the leg, bracing, and stiffener elements are round, solid steel bars. At the radii of the structural elements $0.02 \mathrm{~m}$ (leg), $0.0125 \mathrm{~m}$ (bracing), and $0.007 \mathrm{~m}$ (guy), the total mass of the shaft is $10410 \mathrm{~kg}$, while the mass of all guys is $1230 \mathrm{~kg}$.

The optimal mast scheme is sought retaining the scheme of an industrial mast but varying the topology, shape, and sizing parameters of the mast. The range of guys' clusters from 1 to 10 is explored. Constant data specific to this mast which do not vary in the optimization process are as follows:

(i) Height of the mast: $96 \mathrm{~m}$

(ii) Area of antennas distributed in the top $15 \%$ of mast height: $10.34 \mathrm{~m}^{2}$

(iii) Diameter of auxiliary equipment along the whole mast height: $0.05 \mathrm{~m}$ 
(iv) Wind velocity: $25 \mathrm{~m} / \mathrm{sec}$

(v) Allowable steel stresses: $2.35 \times 10^{8} \mathrm{~N} / \mathrm{m}^{2}$

(vi) Specific weight of steel: $7.70 \times 10^{4} \mathrm{~N} / \mathrm{m}^{3}$

(vii) Young's modulus of steel elements: $2.10 \times 10^{11} \mathrm{~N} / \mathrm{m}^{2}$

(viii) Young's modulus of guys: $1.50 \times 10^{11} \mathrm{~N} / \mathrm{m}^{2}$

(ix) Allowable guy stresses: $1.00 \times 10^{9} \mathrm{~N} / \mathrm{m}^{2}$

(x) Weight factor for the mass of guys: 3

The design parameters along with their characteristics (dimensions in $\mathrm{m}$, forces in $\mathrm{N}$ ) are listed in Table 1.

We treat all the cross section characteristics as continuous variables. After the solution is obtained, the designer should round the radii of structural elements to the safe side and to the available assortment or in-stock values. Consequently, the modified mast structure will be slightly heavier.

The following genetic parameters of EA were chosen after a few numerical experiments:

(i) Population size: 200 individuals

(ii) Number of generations: 200

(iii) Stopping criterion: the first met: the maximum number of generations: 200; stall generations (i.e., if the weighted average change in the objective function value over stall generations is less than function tolerance: $1 e-6)$ : 100; objective function tolerance (i.e., cumulative change in the objective function value over stall generations is less than given function tolerance)

(iv) Crossover probability: 0.8

(v) Crossover type: Laplace crossover [19]

(vi) Mutation type: power mutation [19]

(vii) Penalty type: static, proportional to the extent of constraint violation

Since the EA is a stochastic algorithm whose solution generally cannot be repeated, we take 30 independent numerical experiments. In this case the median solution stabilizes and additional numerical experiments do not change the best and median results significantly. After the EA solution, the best obtained result is refined with pattern search.

Solution time depends on the number of finite element mesh nodes that in turn is determined by the number of typical sections $n_{s}: n=n_{s} \cdot 6+3$. Thirty runs of the program package usually take from 300 to $1600 \mathrm{~min}$.

The final results of mast optimization successively with $1,2, \ldots, 10$ guys' clusters, that is, the total mass of structure $\left(m_{E A+P S}\right.$ in Table 2$)$, width of shaft, and radii of all structural elements after solution with the EA and the subsequent PS, are provided in Table 2. In order to reveal the influence of PS on the quality of the result, the value of total mass obtained only using EA ( $m_{E A}$ in Table 2$)$ is also given. The mass is given in $\mathrm{kg}$, while the geometrical parameters are in $\mathrm{m}$. Also, some relevant data on the optimization process - the total number of objective function evaluations $\left(N_{f}\right)$ in 30 independent numerical experiments and the total time of computations

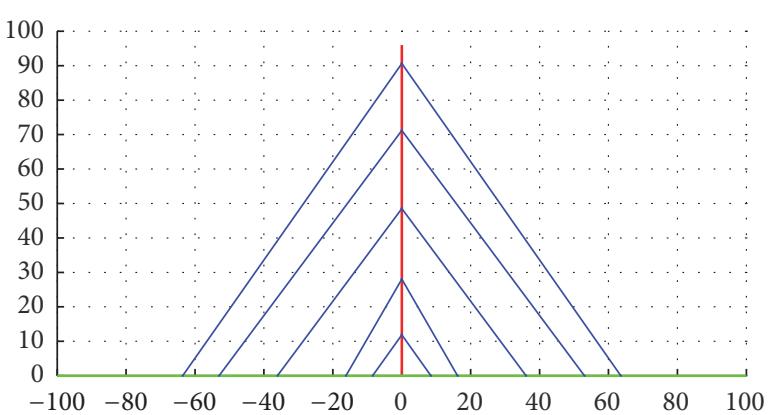

FIGURE 4: The best scheme obtained for the mast.

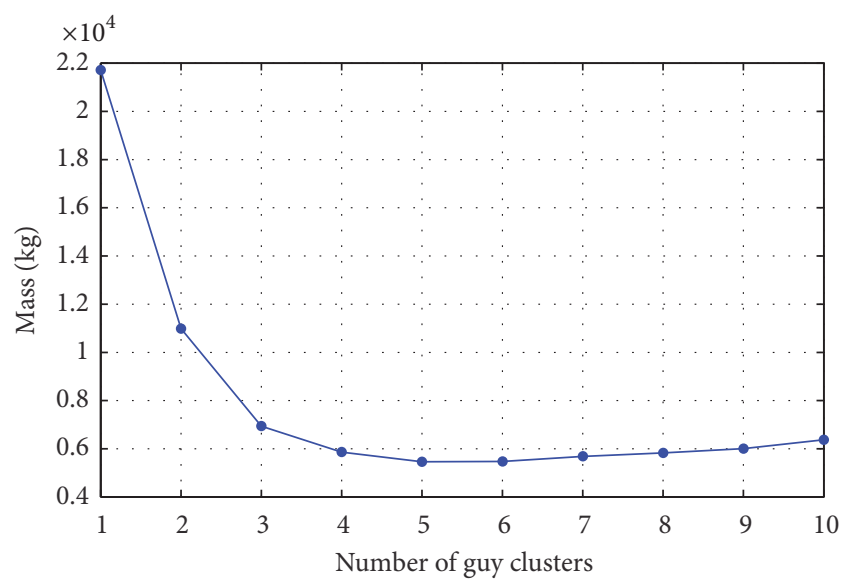

Figure 5: Dependence of the mast mass on the number of guys' clusters.

( $T$, in $\mathrm{h})$-are listed. The pretension forces in the guys of different clusters are not provided in the table due to lack of space; generally, the pretension forces are highest at lowest guys and gradually diminish in higher clusters. The pretension forces (also in the form of prestress) for the masts of 2-5 guys' clusters are provided in Table 3 . Some additional information on the optimal pretensioning of guys may be found also in [10]. The best scheme obtained is depicted in Figure 4.

From the engineering point of view, the most relevant ones are the schemes with 2-5 guys' clusters. Figure 5 definitely shows that the total mass of the mast reduces significantly starting from 3 guys' clusters: the mass of a 3 -level mast is $37 \%$ less than the mass of a 2 -level mast. Introducing more than 4 guys' clusters does not produce a large effect-the mass of a 5-level mast is only $7 \%$ less. Thus, the rational scheme for the analysed masts should possess 3 to 5 guys' clusters.

A closer view of the best three results obtained for the masts with 2 to 5 guys' clusters (Table 3) reveals that the optimal parameters, particularly geometrical, are distributed in rather narrow bounds. In many cases the differences between corresponding parameters do not exceed $10 \%$. One of these determinant geometrical parameters is the width of the shaft. For masts clamped at the foundation this parameter conditions two important factors: the bending stiffness and 
TABLE 3: The main optimal parameters of the best 3 solutions for 2 to 5 guys' clusters masts ( $m$ : total mass of the mast, kg; $w$ : side of the mast, $\mathrm{m} ; n_{s}$ : number of sections; $\alpha$ : tilt angle of bracing elements, deg; $l_{i}$ : attachment level of the $i$ th guys' cluster; $d_{i}$ : anchoring distance of the $i$ th guys' cluster, $\mathrm{m} ; \beta_{i}$ : tilt angle of the guy at the $i$ th level, deg; $T_{p i}$ : prestress force at the $i$ th guy level, $\mathrm{kN} ; \sigma_{p 2}$ : prestress at the $i$ th guy level, MPa; $r_{l, b, g}$ : radii of the leg, bracing, and guy elements, $\mathrm{mm}$ ).

\begin{tabular}{|c|c|c|c|c|c|c|c|c|c|c|c|c|}
\hline & \multicolumn{3}{|c|}{2 guys' clusters } & \multicolumn{3}{|c|}{3 guys' clusters } & \multicolumn{3}{|c|}{4 guys' clusters } & \multicolumn{3}{|c|}{5 guys' clusters } \\
\hline & 1st & 2nd & $3 \mathrm{rd}$ & $1 s t$ & 2nd & $3 \mathrm{rd}$ & 1st & 2nd & $3 \mathrm{rd}$ & 1st & 2nd & $3 \mathrm{rd}$ \\
\hline$m$ & 10983 & 11007 & 11009 & 6941 & 6951 & 6956 & 5862 & 5904 & 5912 & 5459 & 5523 & 5523 \\
\hline$w$ & 1.18 & 1.18 & 1.14 & 0.86 & 0.87 & 0.90 & 0.69 & 0.75 & 0.75 & 0.69 & 0.67 & 0.63 \\
\hline$n_{s}$ & 57 & 57 & 59 & 72 & 74 & 71 & 82 & 81 & 77 & 91 & 85 & 85 \\
\hline$\alpha$ & 35.5 & 35.5 & 35.5 & 37.7 & 36.8 & 37.0 & 40.2 & 38.2 & 39.9 & 33.3 & 40.1 & 42.1 \\
\hline$l_{1}$ & 18 & 18 & 20 & 16 & 17 & 16 & 15 & 12 & 13 & 13 & 11 & 11 \\
\hline$l_{2}$ & 49 & 49 & 51 & 35 & 37 & 34 & 33 & 31 & 28 & 27 & 24 & 26 \\
\hline$l_{3}$ & & & & 65 & 67 & 64 & 54 & 50 & 50 & 45 & 41 & 43 \\
\hline$l_{4}$ & & & & & & & 77 & 75 & 72 & 67 & 61 & 62 \\
\hline$l_{5}$ & & & & & & & & & & 86 & 80 & 80 \\
\hline$d_{1}$ & 23.4 & 25.1 & 25.7 & 18.5 & 18.2 & 18.3 & 15.5 & 11.8 & 12.0 & 7.7 & 9.9 & 9.1 \\
\hline$d_{1}$ & 39.3 & 39.3 & 36.5 & 31.8 & 33.6 & 32.3 & 26.6 & 22.5 & 24.5 & 15.6 & 15.9 & 19.0 \\
\hline$d_{3}$ & & & & 57.4 & 52.3 & 57.2 & 44.1 & 40.1 & 51.7 & 35.5 & 36.6 & 36.1 \\
\hline$d_{4}$ & & & & & & & 53.9 & 58.7 & 58.5 & 55.5 & 58.5 & 49.8 \\
\hline$d_{5}$ & & & & & & & & & & 60.8 & 70.4 & 65.4 \\
\hline$\beta_{1}$ & 37.5 & 35.6 & 37.9 & 40.9 & 43.0 & 41.1 & 44.0 & 45.5 & 47.3 & 52.4 & 47.9 & 50.4 \\
\hline$\beta_{2}$ & 51.3 & 51.3 & 54.4 & 47.7 & 47.8 & 46.5 & 51.2 & 54.1 & 48.8 & 58.1 & 56.4 & 53.9 \\
\hline$\beta_{3}$ & & & & 48.6 & 52.0 & 48.2 & 50.7 & 51.3 & 44.0 & 51.3 & 48.2 & 50.0 \\
\hline$\beta_{4}$ & & & & & & & 55.0 & 52.0 & 50.9 & 51.2 & 46.2 & 51.2 \\
\hline$\beta_{5}$ & & & & & & & & & & 52.9 & 48.6 & 50.7 \\
\hline$T_{p 1}$ & 27.7 & 25.5 & 28.9 & 10.6 & 12.5 & 12.1 & 9.10 & 9.30 & 20.0 & 8.01 & 23.0 & 26.4 \\
\hline$T_{p 2}$ & 20.1 & 21.8 & 17.7 & 10.7 & 9.40 & 10.3 & 7.80 & 12.2 & 8.80 & 5.39 & 12.8 & 14.0 \\
\hline$T_{p 3}$ & & & & 12.8 & 11.5 & 12.7 & 9.60 & 8.80 & 11.1 & 8.99 & 13.7 & 9.80 \\
\hline$T_{p 4}$ & & & & & & & 9.10 & 10.5 & 9.60 & 11.4 & 11.8 & 10.1 \\
\hline$T_{p 5}$ & & & & & & & & & & 8.90 & 10.0 & 10.2 \\
\hline$\overline{\sigma_{p 1}}$ & 361 & 331 & 375 & 138 & 163 & 157 & 119 & 120 & 260 & 104 & 299 & 343 \\
\hline$\sigma_{p 2}$ & 262 & 283 & 230 & 139 & 122 & 134 & 101 & 159 & 114 & 69.8 & 166 & 182 \\
\hline$\sigma_{p 3}$ & & & & 167 & 149 & 165 & 124 & 114 & 144 & 116 & 179 & 127 \\
\hline$\sigma_{p 4}$ & & & & & & & 118 & 136 & 125 & 147 & 154 & 131 \\
\hline$\sigma_{p 5}$ & & & & & & & & & & 114 & 130 & 132 \\
\hline$r_{l}$ & 28.0 & 28.0 & 28.0 & 22.5 & 22.3 & 22.5 & 20.6 & 20.3 & 20.8 & 19.1 & 19.7 & 19.4 \\
\hline$r_{b}$ & 12.0 & 12.0 & 12.0 & 10.0 & 10.0 & 10.2 & 8.6 & 9.0 & 8.9 & 8.1 & 8.2 & 8.1 \\
\hline$r_{g}$ & 8.1 & 8.2 & 8.3 & 5.5 & 5.6 & 5.5 & 4.9 & 4.95 & 4.8 & 4.6 & 4.4 & 4.6 \\
\hline
\end{tabular}

the magnitude of axial forces in the legs of the shaft. The axial forces in the legs diminish with the increasing distance between the legs, at the expense of increasing bending stiffness. Large bending stiffness is not acceptable, since even small shaft displacements cause significant bending moments at the foundation. Due to this, greater guy stiffness is required in the lower guys.

The results also indicate that a small number of guys' clusters determine very high prestress levels in the lower guys, for example, for 2 guys' clusters the values of prestress exceed $300 \mathrm{MPa}$. The same holds for the 5-level mast: the global stability condition does not allow for diminishing bending stiffness, and this, in turn, requires larger prestress forces in the lower guys for alignment of stresses. A large prestress level has an adverse influence on metal fatigue due to the vibrations of cables.

As to the tilt angle of bracing elements, in all of the best solutions for a small number of guys' clusters it equals 35.5 degrees - this corresponds well to the optimal values of tilt angle reported in [8]. This can be explained by the fact that the determinant factor in such structures is the bending of the shaft. In larger numbers of guys' clusters the shear force which determines the stresses in bracing elements is relatively higher.

Another interesting point is the fact that one of the most stable parameters is the tilt angle of the uppermost guys: independently of the number of guys' clusters, its value is close to 50 degrees. 


\section{Conclusions}

A technique for simultaneous topology/shape/sizing optimization of guyed telecommunication mast is suggested. It comprises four independent parts: the optimization algorithm, finite element linear static analysis program, meshing preprocessor, and postprocessor for evaluation of constraints according to the Eurocodes and the objective function-the total mass of the shaft and guys. With "one button click" the programs yield an optimal scheme for the mast, including all dimensions of structural elements and pretension forces in the guys. The whole optimization loop takes up to $1600 \mathrm{~min}$ on a typical PC and provides the designer with an initial suggestion for all elements of the mast structure, thus accelerating the design process.

Using the proposed technique, the typical $96 \mathrm{~m}$ steelguyed mast carrying a standard antenna cluster was optimized. The optimization of the mast with different sets of design parameters definitely shows that the most relevant schemes of the mast have three to five guys' clusters, with the optimal scheme being the mast with five guys' clusters. Introducing more guys' clusters leads to a slight increase in the mass of the mast.

Analysis of the three best solutions for each 3- to 5-guycluster mast scheme reveals some stable ranges of design parameters. The optimal number of typical sections along the height of the mast is around 57 for a 2-level mast, 73 for a 3level mast, 81 for a 4-level mast, and $85-90$ for a 5-level mast. The optimal width of the mast side is around $1.18,0.87,0.72$, and $0.67 \mathrm{~m}$, correspondingly. The attachment levels of each guys' cluster and guys' anchoring distances from the shaft also are very close for all of the best solutions.

As stated in prior research [11], the comparison of the optimized $96 \mathrm{~m}$ tall mast with the typical industrial design shows possibilities for significant reduction in expenditures on steel.

\section{Conflicts of Interest}

The authors declare that there are no conflicts of interest regarding the publication of this paper.

\section{References}

[1] C. Gantes, R. Khoury, J. J. Connor, and C. Pouangare, "Modeling, loading, and preliminary design considerations for tall guyed towers," Computers and Structures, vol. 49, no. 5, pp. 797805, 1993.

[2] B. W. Smith, Communication Structures, Thomas Telford, London, United Kingdom, 2007.

[3] Y. M. F. Wahba, M. K. S. Madugula, and G. R. Monforton, "Evaluation of non-linear analysis of guyed antenna towers," Computers and Structures, vol. 68, no. 1-3, pp. 207-212, 1998.

[4] Y.-L. He, X. Ma, and Z.-M. Wang, "Nonlinear discrete analysis method for random vibration of guyed masts under wind load," Journal of Wind Engineering and Industrial Aerodynamics, vol. 91, no. 4, pp. 513-525, 2003.

[5] M. Gioffrè, V. Gusella, A. L. Materazzi, and I. Venanzi, "Removable guyed mast for mobile phone networks: wind load modeling and structural response," Journal of Wind Engineering and Industrial Aerodynamics, vol. 92, no. 6, pp. 463-475, 2004.

[6] N. A. Jasim and A. C. Galeb, "Optimum design of square freestanding communication towers," Journal of Constructional Steel Research, vol. 58, no. 3, pp. 413-425, 2002.

[7] C. Preeti and K. Jagan Mohan, "Analysis of transmission towers with different configurations," Jordan Journal of Civil Engineering, vol. 7, no. 4, pp. 450-460, 2013.

[8] D. Jatulis, A. Juozapaitis, and P. Vainiūnas, "Optimal design of lattice towers made up of solid round steel bars," in Proceedings of the 10th International Conference Modern Building Materials, Structures and Techniques: selected papers, P. Vainiūnas and E. K. Zavadskas, Eds., pp. 641-645, Technika, Lithuania, 2010.

[9] R. Belevičius, D. Jatulis, and D. Šešok, "Optimization of tall guyed masts using genetic algorithms," Engineering Structures, vol. 56, pp. 239-245, 2013.

[10] R. Belevičius, D. Jatulis, and D. Šešok, "Some insights on the optimal schemes of tall guyed masts," Journal of Civil Engineering and Management, vol. 19, no. 5, pp. 749-758, 2013.

[11] R. Belevičius, D. Jatulis, D. Rusakevičius, and D. Šešok, "Optimal Schemes for Tall Guyed Telecommunication Masts," in Proceedings of The Fifteenth International Conference on Civil, Structural and Environmental Engineering Computing, J. Kruis, Y. Tsompanakis, and B. H. V. Topping, Eds., Civil-Comp Press, Prague, Czech Republic, September 2015.

[12] http://se.mathworks.com/products/global-optimization/.

[13] Eurocode 1, Actions on structures-General action-Part 1-4: wind action, European Committee for Standardization (CEN, Brussels, 2005.

[14] Eurocode 3, Design of steel structures-Towers and masts-Part 3-1: towers, masts and chimneys, European Committee for Standardization (CEN), Brussels, 2006.

[15] ISO 12494:2001, “Atmospheric Icing on Structures," 2001.

[16] T. G. Kolda, R. M. Lewis, and V. J. Torczon, "A generating set direct search augmented Lagrangian algorithm for optimization with a combination of general and linear constraints," Tech. Rep. SAND2006-5315, Sandia National Laboratories, United States, 2006.

[17] Eurocode 3, Design of steel structures-Part 1-1: general structural rules, European Committee for Standardization (CEN), Brussels, 2005.

[18] O. C. Zienkiewicz, R. L. Taylor, and D. D. Fox, The finite element method for solid and structural mechanics, Elsevier/Butterworth Heinemann, Amsterdam, Seventh edition, 2014.

[19] K. Deep, K. P. Singh, M. L. Kansal, and C. Mohan, "A real coded genetic algorithm for solving integer and mixed integer optimization problems," Applied Mathematics and Computation, vol. 212, no. 2, pp. 505-518, 2009. 


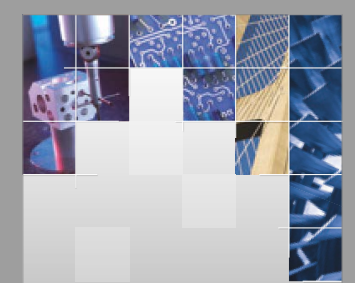

\section{Enfincering}
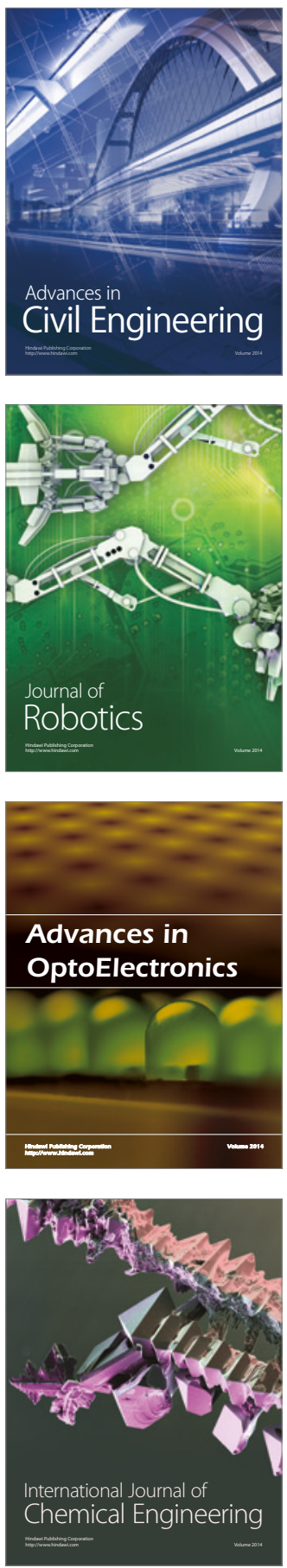

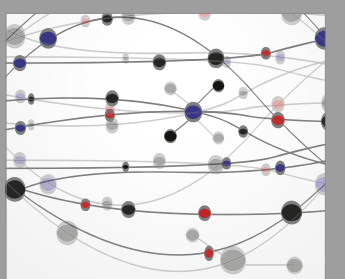

The Scientific World Journal

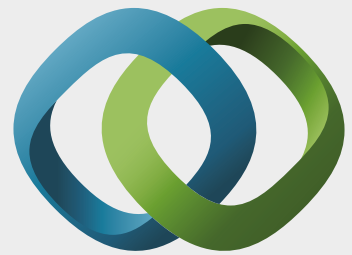

\section{Hindawi}

Submit your manuscripts at

https://www.hindawi.com
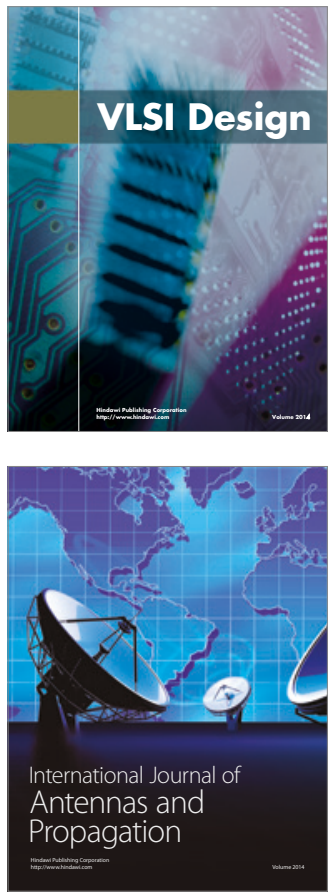

\section{Rotating}

Machinery
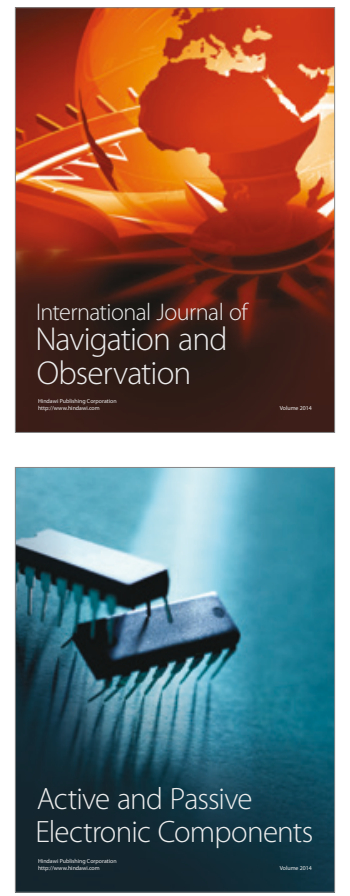
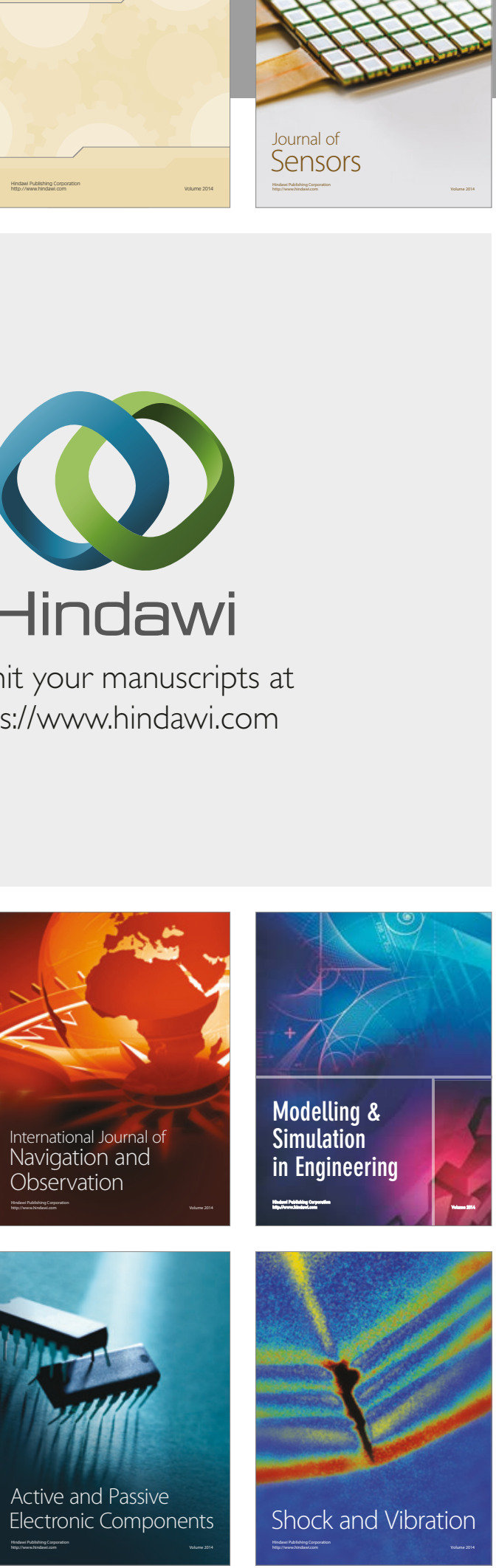
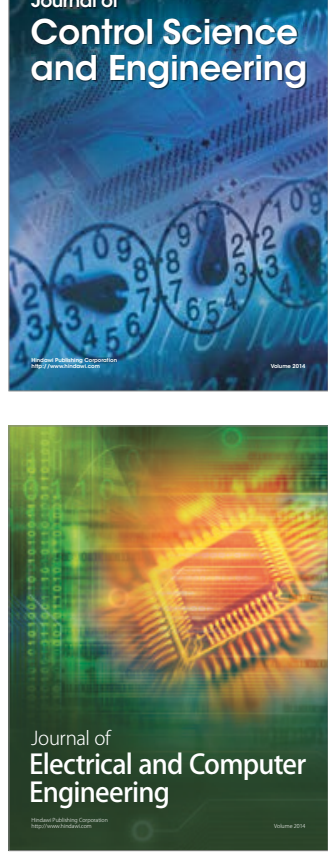

Distributed

Journal of

Control Science

and Engineering
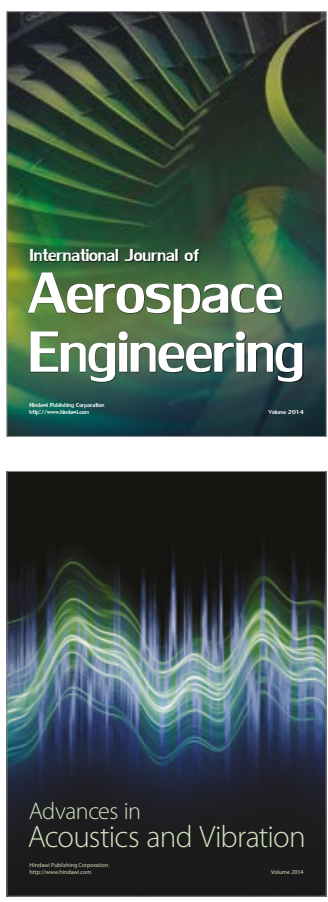

Sensor Networks 